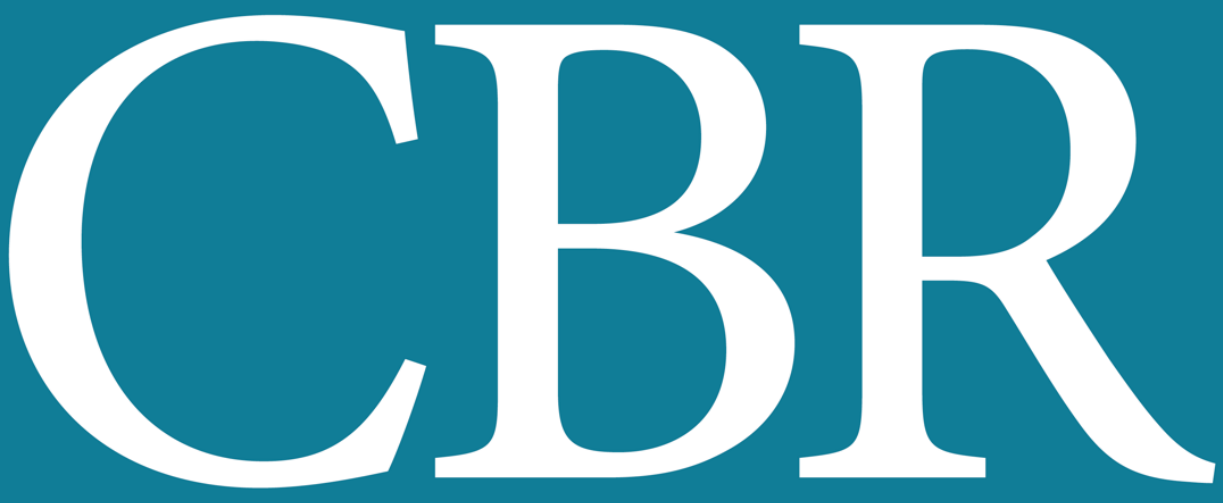

INTERNATIONAL JOURNAL OF CANCER AND BIOMEDICAL RESEARCH

https://jcbr.journals.ekb.eg

Editor-in-chief

Prof. Mohamed Labib Salem, PhD

Application of EGFR, ki 67 and GFAP as a panel for the diagnosis and grading of astrocytomas

Aliaa Atef and Mohamed El-Rashidy 


\section{Welcome letter from Editor-in-Chief}

Welcome to the Int J Cancer and Biomedical Research (IJCBR)!

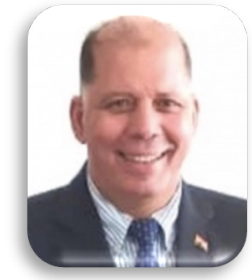

It is with great pleasure that I write this editorial to welcome you to the IJCBR. This journal provides a platform for publication of original and reviews research articles, short communications, letter to editor, thesis abstract, conference report, and case studies. These types of publication are directed at the interface of the fields of cancer and biomedical research.

The IJCBR relies on a distinguished expert of the Advisory and Editorial Board Members from the top international league covering in depth the related topics. They timely review all manuscripts and maintain highest standards of quality and scientific methodology and ethical concepts. Meanwhile, we take all possible means to keep the time of the publication process as short as possible.

I take this chance to welcome your contributions to the IJCBR and have every expectation that it will soon become one of the most respected journals in both the fields of cancer and biomedical research.

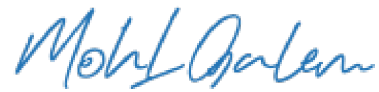

Mohamed L. Salem,

Editor in Chief 


\title{
Application of EGFR, ki 67 and GFAP as a panel for the diagnosis and grading of astrocytomas
}

\author{
Aliaa Atef and Mohamed El-Rashidy \\ Pathology Department, Faculty of Medicine, Tanta university, Egypt
}

\section{ABSTRACT}

\section{ARTICLE INFO}

Background: Astrocytic tumors are the most common primary central nervous system tumors. WHO grading scheme is based on the presence or absence of the following four histological parameters using haematoxylin and eosin (H\&E) staining: cellular atypia (WHO grade II), mitotic figures (WHO grade III), endothelial proliferation, and/or necrosis (WHO grade IV). Immunohistochemistry (IHC) has become an essential tool in diagnosis of brain tumors and helps in predicting the prognosis of certain brain including astrocytomas. Aim: Study the immunohistochemical expressions of (Epidermal growth factor receptor (EGFR), Ki67 and Glial fibrillary acidic protein (GFAP)) in different grades of astrocytomas. Materials and Methods: This study included 44 cases of astrocytomas classified as: 3 pilocytic astrocytomas, 6 diffuse low grade astrocytomas, 15 anaplastic astrocytomas and 20 glioblastoma multiforms. Immunohistochemical staining of all cases using EGFR, Ki67 and GFAP was done. Results: EGFR showed positive membranous and cytoplasmic expression in 33 (75\%) cases, GFAP positive staining was detected in $38(86.4 \%)$ of studied cases while all astrocytomas of different grades showed ki67 positivity with variable degrees with the mean \pm SEM of Ki67 LI $17.76 \% \pm 2.46$. There was statistically significant relation between EGFR, Ki 67 and GFAP expression and tumor grade. Conclusions: EGFR, Ki 67 and GFAP should be used in combination as a panel side by side with established histological criteria of malignancy and WHO grading system for accurate diagnosis and grading of astrocytic tumors.

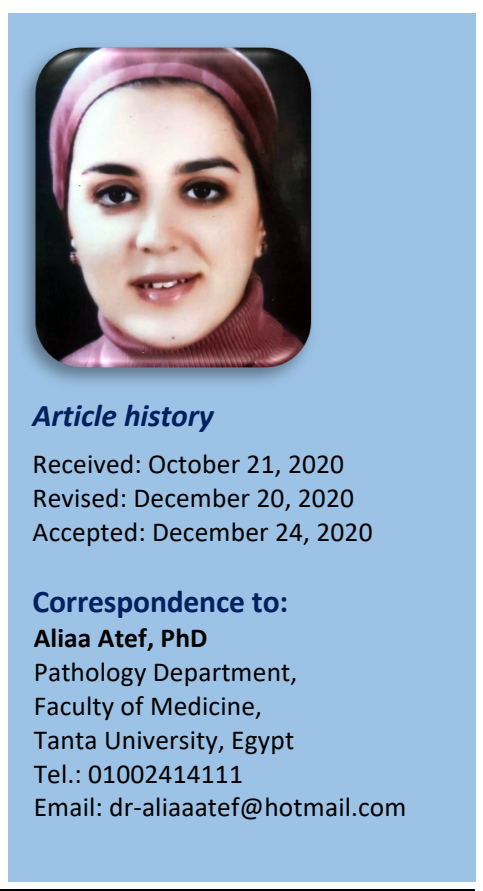

Editor-in-Chief: Prof. M.L. Salem, PhD - Article DOI: 1010.21608/jcbr.2020.47290.1085

\section{INTRODUCTION}

Central nervous system tumors (CNS) constitute $1-2 \%$ of adult neoplasms. According to cell type, WHO (2016) classification divided gliomas into astrocytomas, oligodendrogliomas, and ependymomas. Astrocytomas are the most common primary central nervous system tumors. According to the 2016 WHO classification, the astrocytic neoplasms were grouped into two major categories; diffusely invasive astrocytoma (diffuse astrocytoma, anaplastic astrocytoma, glioblastoma) and the relatively more circumscribed tumors (pilocytic, pilomyxoid astrocytoma, pleomorphic xanthoastrocytoma and subependymal giant cell astrocytoma). The neuropathological grading of infiltrating astrocytomas consisted of a three grades (II, III and IV) while grade I represents non-infiltrating astrocytomas (Louis et al., 2016).
WHO grading scheme is based on the presence or absence of four histological parameters: depending on the assessment of features such as cellular atypia (WHO grade II), mitotic figures (WHO grade III), endothelial proliferation, and/or necrosis (WHO grade IV), while WHO grade I showing only increased cellular proliferation with lacking of all the previously mentioned criteria. All these histological parameters can be deteced by haematoxylin and eosin (H\&E) staining (Popova et al., 2014). Based on morphological criteria, this classification remains unsatisfactory with variable rates of diagnostic pitfalls. Therefore, a well-founded diagnostic evaluation has become a necessity for security of the upcoming management and therapy decisions (Belghali et al., 2017).

Immunohistochemistry (IHC) has been essential in the diagnosis of brain tumors. Despite the 
conventional H\&E staining is the mainstay for histopathologic diagnosis, IHC played a great role in differential diagnosis and in improving the diagnostic accuracy of CNS tumors. The application of a panel of selected immunostains is very helpful in diagnostically challenging cases. IHC was also found to be of great help in predicting the prognosis of certain brain tumors including astrocytomas (Goyal et al, 2015).

Many growth factors and their receptors play vital roles in cell division, proliferation and differentiation. These receptors are expressed on the surface of cancer cells. One of these receptors is the epidermal growth factor receptor (EGFR), which is the first member of ErbB family of receptor tyrosine kinases (RTK) important in cell development and proliferation. EGFR is expressed in a large number of tumor types, including brain tumors. EGFR can be one of the promising molecular immunohistochemical markers for the prognosis and grading of astrocytomas (Carvalho et al., 2014). The EGFR protein has an extracellular ligand-binding domain, a transmembrane region and an intracellular domain with intrinsic protein-tyrosine kinase activity. Ligand binding of the EGFR activates the EGFR tyrosine kinase which phosphorylates proteins in the signal transduction pathway that leads to activation of genes that regulate cell proliferation, angiogenesis, motility, invasion and metastasis (Abdulghani et al., 2019).

The proliferative index is a potent biological factor that estimates the growth of neoplasms quantitatively and thus will aid in predicting the prognosis of different tumors. One of the most potent methods for assessing the proliferative index in brain tumors is the Ki-67 labeling index (Ki-67 LI). Ki-67 is a nuclear antigen expressed in the $G 1, S, G 2$, and $M$ phases of the cell cycle but absent in the resting phase and its expression is assessed using $\mathrm{Ki}-67 \mathrm{LI}$ which represents the percentage of Ki-67 positive cells (Das et al., 2018).

In addition to detection and measurement of the proliferative activity of astrocytomas by EGFR and Ki67 respectively, Glial fibrillary acidic protein (GFAP) can be applied along with the previous two markers for assessing the prognosis and diagnosis of astrocytic tumors.
GFAP is one of the major cytoplasmic intermediate filaments and is the main cytoskeletal component of astrocytes. GFAP is widely known as a diagnostic marker for astrocytic tumors with its expression seen in normal, reactive, and neoplastic astrocytes. Most of the astrocytic tumors show GFAP positivity except protoplasmic astrocytoma (WHO Grade II) where GFAP immunoreactivity is either scanty or absent (Jaiswal, 2016).

This work aimed to study the immunohistochemical expressions of EGFR, Ki67 and GFAP in different grades of astrocytoma to assess the cellular proliferation degree and the cell lineage of studied cases and to correlate their expressions with the grade and other clinical and histopathological parameters to explore the prognostic value of these markers.

\section{MATERIALS AND METHODS}

This study was carried out retrospectively on 44 brain biopsies diagnosed as astrocytoma divided into 4 grades according to WHO grading (2016): 3 cases of pilocytic astrocytomas (Grade I), 6 diffuse low grade astrocytoma (Grade II), 15 anaplastic astrocytomas (Grade III) and 20 glioblastoma multiforms (Grade IV) (Louis et al., 2016). Samples were collected as formalinfixed, paraffin-embedded tissue blocks, with H\&E stained slides from the archives of the pathology department of faculty of medicine, Tanta University where this study took place) and private labs (36 cases) or received as fresh specimens ( 8 cases) during the period between February 2019 and July 2020. This study was approved by the research ethics committee of faculty of medicine of Tanta university.

\section{Immunohistochemistry}

It was performed using the immunoperxoidase method on $4 \mu$-thick sections from the paraffinembedded blocks. Tissue sections were deparaffinized in xylene and rehydrated in descending grades of alcohol $(100,95,85$ and $75 \%$ ethanol) and blocked with 3\% hydrogen peroxide for $15 \mathrm{~min}$ at room temperature. Antigen retrieval was performed after heating in citrate buffer at $98^{\circ} \mathrm{C}$ for $10 \mathrm{~min}$. Pretreated sections were incubated with rabbit polyclonal EGFR antibody (1:200, Thermo Scientific, Egypt 
Catalog \# PA1-1110), Ki67 a rat monoclonal antibody (1:100, Thermo Scientific, Egypt, Catalog \# 13-5698-82) and GFAP a mouse monoclonal antibody $(1 \mu \mathrm{g} / \mathrm{ml}$, Thermo Scientific, Egypt, Catalog \# MA5-12023) was also applied to the sections at $4^{\circ} \mathrm{C}$ overnight and incubated with secondary antibody (HRPRabbit/Mouse) for $30 \mathrm{~min}$ at $37^{\circ} \mathrm{C}$. The signal was detected with 3,3'-diaminobenzidine solution. using a light microscope. As a negative control, a section was processed in which the primary antibody was changed by PBS. Immunohistochemical staining was evaluated independently by two pathologists.

\section{Interpretation of immunohistochemical Staining}

Every immunohistochemically stained slide was scanned and the fields that reflect the best of the overall immunostaining were chosen and captured using light microscope attached with an imaging system (Lieca DM 2000, Lieca Microscopy and Scientific Instruments Group Germany).

EGFR positive cells showed membranous and / or cytoplasmic staining. A positive stain is indicated by a golden brown precipitate at the site of specific cellular antigen localization. Immunohistochemical staining for EGFR was graded according to percentage of positive tumor cells as follows: 0 (no cell stained), +1 (< $5 \%$ tumor cells), +2 (5- 50\% cells), and +3 (> 50\% cells). For statistical analysis, a score of 0 and 1 were considered negative and a score of 2 or 3 was considered positive (Abdulghani et al., 2019).

Ki67 positively stained cells showed brown diffuse or granular nuclear reactivity. Immunostaining was evaluated at the low-power examination. Fields from the area of maximal positivity were chosen for counting. In glioblastomas, areas free from necrosis or capillary endothelial proliferation were selected. The Ki-67 LI represents the number of Ki-67 positive tumor nuclei expressed as a percentage of a total number of tumor nuclei counted using high-power magnification $(\times 400)$. A total of at least 1000 tumor nuclei were counted in each case. The mean of Ki67 LI was tabulated (Das et al., 2018).
GFAP positivity was qualitatively assessed by the intensity of the immunostaining: 0 (negative), +1 (weak staining), +2 (moderate staining) and +3 (intense staining) (Belghali et al., 2017).

\section{Statistical analysis}

Statistical analysis was done using statistical package for the social sciences (SPSS). The analysis of the relation between markers expression and the clinicopathological characteristics was performed using the Kruskal Wallis test, Fisher's exact test or qui square $(\chi 2)$ test with Yates continuity correction. $P$-value < 0.05 was considered statistically significant.

\section{RESULTS}

The age of patients at the time of surgery ranged between 8 and 82 years; the mean age was 53.8 years. Gender distribution showed slight male predominance with 25 males and 19 females. Cases were divided into low grade (LG) astrocytomas (3 cases of pilocytic astrocytomas (Grade I) and 6 diffuse low grade astrocytoma (Grade II); and high grade (HG) astrocytoma (15 anaplastic astrocytomas (Grade III) and 20 glioblastoma multiforms (grade IV) (Fig. 1,2,3). Regarding tumor site, 22 cases were frontal, 8 cases were parietal, 5 cases were temporal while 9 cases were occipital.

\section{Immunohistochemical staining results of EGFR}

EGFR showed positive membranous and cytoplasmic expression in 33 (75\%) cases out of 44 studied cases including: 4 LG astrocytomas (1 case of grade I and 3 cases of grade II) (Fig. 4); and 29 HG astroctyomas (11 cases of grade III astrocytoma and 18 cases of grade IV) (Fig. 5) (Table 1). The relation between the immunohistochemical staining results of EGFR and the clinicopathological characters were summerized in Table (2). There was a statistically significant relation between EGFR expression and tumor grade where EGFR expression increased with higher grades $(p=$ 0.021 ). Also the percentage of staining was significantly increased in the group of $\mathrm{HG}$ astrocytomas than in LG astrocytomas $(p=0.03)$.

\section{Immunohistochemical staining results of Ki67}

All astrocytomas of different grades showed ki67 positivity with variable degrees. The mean 
\pm Standard error of the mean (SEM) of Ki67 LI was $17.76 \% \pm 2.46$ with a range of $0 \%$ to $70 \%$ (Fig. 6, 7). The relation between the mean Ki67 $\mathrm{LI}$ and the clinicopathological characters were summerized in Table (3). There was a statistically significant relation between Ki67 LI and tumor grade where Ki67 $\mathrm{LI}$, and in turn tumor proliferation, increased with higher grades $(p>0.001)$.

\section{Immunohistochemical staining results of GFAP}

GFAP positive cytoplasmic expression was variable according to the tumor grade. Positive staining was detected in 38 cases $(86.4 \%)$ of studied cases. Areas of necrosis in glioblastomas showed no immunostaining with the palisaded cells showing positive staining. The percentage of GFAP expression was higher in LG astrocytomas (all cases of grade I and grade II (100\%) (Fig. 8); than in HG astroctyomas (13 cases (86.7\%) of grade III astrocytoma and 16 cases (80\%) of grade IV) (Fig. 9). The intensity of GFAP expression was inversely related to tumor grade with decreased intensity in higher grades $(p=0.015)$ (Table 4). The relation between the immunohistochemical staining results of GFAP and the clinicopathological characters were summerized in Table (5). There was a statistically significant inverse relation between GFAP expression and tumor grade where GFAP expression decreased with higher grades $(p=$ 0.026).

\section{DISCUSSION}

Astrocytic tumors are the most common primary tumors of the brain that have rapid progression and invasiveness. The current WHO classification of astrocytic tumors has its limitations in predicting prognosis and diagnosis, hence the need for additional factors.
In spite of the advances in the prognosis, diagnosis and treatment modalities, the prognosis of these tumor patients remains poor. Therefore, in order to identify accurate prognostic factors for astrocytomas and evaluate the effectiveness of appropriate treatment, a proper investigation of the molecular mechanisms and carcinocinogenesis of these tumors with the discovery of new molecular markers has become mandatory ( $\mathrm{Hu}$ et al., 2013).

In the present study, we intended to assess the efficacy of EGFR, Ki67 and GFAP in diagnosis and prognosis of astrocytomas especially their ability to detect the grade of astrocytoma side by side with the WHO grading system.

EGFR serves as an important and wellcharacterized mitogenic factor in several ectodermal tissues, including glial cells. EGFR activation is involved in cell differentiation, proliferation, and migration (Burel-Vandenbos et al., 2011). In our study, EGFR showed positive cytoplasmic and/or membranous expression in $75 \%$ of studied astrocytomas with statistically significant relation between EGFR expression and tumor grade. EGFR expression increased with higher grades $(p=0.021)$ with significantly increased intensity of staining in HG astrocytomas $(p=0.03)$.

Maiti et al. (2008) results were in approval with ours. They stated that the percentage of EGFR positive cells was $2.17+/-0.475$ in Grade II astrocytoma, $12.63+/-1.79$ in Grade III astrocytoma and $22.86+/-1.792$ in glioblastoma. As well, a significant increase in EGFR percentage of expression from lower to higher grades was also detected. In 2013, Hu et al., similarly noted that EGFR expression was associated with glioma grade.

Table 1. The immunohistochemical staining results of EGFR in studied cases:

\begin{tabular}{|c|c|c|c|c|c|c|c|c|c|c|c|}
\hline \multirow{3}{*}{\multicolumn{2}{|c|}{ Astrocytoma }} & \multicolumn{8}{|c|}{ Immunohistochemical expression of EGFR } & \multirow{3}{*}{$x^{2}$} & \multirow{3}{*}{$\boldsymbol{P}$} \\
\hline & & \multicolumn{2}{|c|}{$\begin{array}{c}0 \\
\text { (Negative) }\end{array}$} & \multicolumn{2}{|c|}{$\begin{array}{c}+1 \\
\text { (Negative) }\end{array}$} & \multicolumn{2}{|c|}{$\begin{array}{c}+2 \\
\text { (Positive) }\end{array}$} & \multicolumn{2}{|c|}{$\begin{array}{c}+3 \\
\text { (Positive) }\end{array}$} & & \\
\hline & & No & $\%$ & No & $\%$ & No & $\%$ & No & $\%$ & & \\
\hline \multirow{2}{*}{$\begin{array}{l}\text { Low grade } \\
\qquad(n=9)\end{array}$} & Grade I ( $n=3)$ & 2 & $66.6 \%$ & 0 & $0 \%$ & 1 & $33.4 \%$ & 0 & $0 \%$ & \multirow{4}{*}{4.1} & \multirow{4}{*}{$0.03^{*}$} \\
\hline & Grade II ( $n=6)$ & 2 & $33.3 \%$ & 1 & $16.7 \%$ & 3 & $50 \%$ & 0 & $0 \%$ & & \\
\hline \multirow{2}{*}{$\begin{array}{l}\text { High grade } \\
\qquad(n=35)\end{array}$} & Grade III ( $n=15)$ & 1 & $6.7 \%$ & 3 & $20 \%$ & 7 & $46.7 \%$ & 4 & $26.6 \%$ & & \\
\hline & Grade IV $(n=20)$ & 0 & $0 \%$ & 2 & $10 \%$ & 5 & $25 \%$ & 13 & $65 \%$ & & \\
\hline
\end{tabular}

*Statistically significant $(\mathrm{P}<0.05) \cdot \times 2$ : Chi-square test. 
Table 2. The association between EGFR expression and the clinicopathological characters of studied cases:

\begin{tabular}{|l|c|c|c|c|}
\hline Variables & $\begin{array}{c}\text { Negative } \\
\text { (0\&+1) } \\
\mathbf{N = 1 1}\end{array}$ & $\begin{array}{c}\text { Positive } \\
\mathbf{+ 2 \& + 3 )} \\
\mathbf{N = 3 3}\end{array}$ & $\boldsymbol{X}^{\mathbf{2}}$ & $\boldsymbol{P}$ \\
\hline Age & & & & \\
$<50$ (20) & 6 & 14 & 0.5 & $\mathbf{0 . 4 7}$ \\
$>50$ (24) & 5 & 19 & & \\
\hline Sex & & & & \\
Male (25) & 7 & 18 & 1.66 & $\mathbf{0 . 1 9}$ \\
Female (19) & 4 & 15 & & \\
\hline Tumor site & & & & \\
Frontal (22) & 8 & 14 & & \\
Parietal (8) & 2 & 6 & 4.3 & $\mathbf{0 . 2 0}$ \\
Temporal (5) & 0 & 5 & & \\
Occipital (9) & 1 & 8 & & \\
\hline Grade & & & & \\
Grade I (3) & 2 & 1 & & $\mathbf{0 . 0 2 1 *}$ \\
Grade II (6) & 3 & 3 & 5.3 & \\
Grade III (15) & 4 & 11 & & \\
Grade IV (20) & 2 & 18 & & \\
\hline
\end{tabular}

*Statistically significant $(P<0.05) . \chi 2$ : Chi-square test

Table 3. The association between $\mathrm{Ki} 67 \mathrm{LI}$ and the clinicopathological characters of studied cases.

\begin{tabular}{|l|c|c|}
\hline Variables & Ki67 LI (Mean \pm SEM) & $P$ \\
\hline Age & $17.25 \% \pm 2.36$ & $\mathbf{0 . 9 1}$ \\
$<50(20)$ & $18.47 \% \pm 2.38$ & \\
$>50(24)$ & & \\
\hline Sex & $18.03 \% \pm 3.10$ & $\mathbf{0 . 9 0}$ \\
Male (25) & $17.46 \% \pm 3.97$ & \\
Female (19) & & \\
\hline Tumor site & $17.62 \% \pm 4.07$ & $\mathbf{0 . 9 9}$ \\
Frontal (22) & $17.14 \% \pm 3.52$ & \\
Parietal (8) & $18.40 \% \pm 3.65$ & \\
$\quad$ Temporal (5) & $17.65 \% \pm 4.83$ & \\
Occipital (9) & $1.42 \% \pm 0.64$ & \\
\hline Grade & $6.75 \% \pm 1.26$ & $\mathbf{0 . 0 0 1 *}$ \\
Grade I (3) & $23.56 \% \pm 2.25$ & \\
Grade II (6) & $38.63 \% \pm 3.45$ & \\
Grade III (15) & \\
Grade IV (20) & & \\
\hline * Statistically significant $(P<0.05)$, SEM: Standard error of \\
the mean.
\end{tabular}

EGFR positive staining was observed in $22.2 \%$ of grade I, $44.6 \%$ of grade II, $71.2 \%$ of grade III and $88.6 \%$ of grade IV. EGFR positivity was significantly higher in the high grade gliomas (III and IV) than in the low grade gliomas ( $\mathrm{P}=0.021)$. They added as well that marked EGFR staining, +2 or +3 was found in $40,78.4$ and $90.3 \%$ of grade II, III and IV gliomas respectively.

Similarly, Popova et al. (2014), They noticed that EGFR positivity was noted in all studied glioma subtypes with the percentage of EGFR positive cells different significantly, from a few scattered immunoreactive cells to staining almost all tumor cells. In contrast with our results, they noticed that despite $45 \%$ of low-grade gliomas, $57 \%$ of high-grade gliomas and $58 \%$ of GBMs were positive, strong EGFR expression was detected independently from WHO grades.

Another study by Carvalho et al. (2014), noticed cytoplasmic expression of EGFR protein in $75 \%$ of astrocytomas, and $24 \%$ of the astrocytomas showed nuclear localization. They explained EFGR nuclear expression by the translocation of the EGFR protein from the cell surface to the nucleus, as other ErbB family member proteins, by endocytosis which was attributed to its different roles in cell proliferation, tumor progression, DNA repair, and replication.

Few other studies showed different results. An early study by Agosti et al. in 1992, observed EGFR positivity in $37 \%$ of glioblastomas while pilocytic astrocytoma grade I, grade II and anaplastic astrocytoma grade III were EGFR negative. Later in 2009, Guillaudeau et al. also found frequent EGFR expression in glioblastomas with no staining in GI, GII and GIII tumors.

Table 4. The immunohistochemical staining results of GFAP in studied cases

\begin{tabular}{|c|c|c|c|c|c|c|c|c|c|c|c|}
\hline \multirow{3}{*}{\multicolumn{2}{|c|}{ Astrocytoma }} & \multicolumn{8}{|c|}{ Immunohistochemical expression of GFAP } & \multirow{7}{*}{$\begin{array}{l}X^{2} \\
8.43\end{array}$} & \multirow{4}{*}{$\begin{array}{c}\boldsymbol{P} \\
0.015^{*}\end{array}$} \\
\hline & & \multicolumn{2}{|c|}{$\begin{array}{c}0 \\
\text { (Negative) }\end{array}$} & \multicolumn{2}{|c|}{$\begin{array}{c}+1 \\
\text { (Weak) }\end{array}$} & \multicolumn{2}{|c|}{$\begin{array}{c}+2 \\
\text { (Moderate) }\end{array}$} & \multicolumn{2}{|c|}{$\begin{array}{c}+3 \\
\text { (Intense) }\end{array}$} & & \\
\hline & & No & $\%$ & No & $\%$ & No & $\%$ & No & $\%$ & & \\
\hline \multirow{2}{*}{$\begin{array}{l}\text { Low grade } \\
(n=9)\end{array}$} & Grade I $(n=3)$ & 0 & $0 \%$ & 0 & $0 \%$ & 1 & $33.4 \%$ & 2 & $66.6 \%$ & & \\
\hline & Grade II (n=6) & 0 & $0 \%$ & 0 & $0 \%$ & 3 & $50 \%$ & 3 & $50 \%$ & & \\
\hline \multirow{2}{*}{$\begin{array}{l}\text { High grade } \\
\quad(n=35)\end{array}$} & Grade III ( $n=15)$ & 2 & $13.3 \%$ & 4 & $26.6 \%$ & 6 & $39.9 \%$ & 3 & $20.2 \%$ & & \\
\hline & Grade IV $(n=20)$ & 4 & $20 \%$ & 10 & $50 \%$ & 5 & $25 \%$ & 1 & $5 \%$ & & \\
\hline
\end{tabular}

*Statistically significant $(\mathrm{P}<0.05)$. $\chi 2$ : Chi-square test. 
Table 5. The association between GFAP expression and the clinicopathological characters of studied cases:

\begin{tabular}{|l|c|c|c|c|}
\hline Variables & $\begin{array}{c}\text { Negative } \\
\text { GFAP } \\
\text { N= 6 }\end{array}$ & $\begin{array}{c}\text { Positive } \\
\text { GFAP } \\
\text { N=38 }\end{array}$ & $\boldsymbol{X}^{\mathbf{2}}$ & $\boldsymbol{P}$ \\
\hline Age & 2 & 18 & 3.9 & $\mathbf{0 . 2 8}$ \\
$<\mathbf{5 0}$ (20) & 4 & 20 & & \\
$>\mathbf{5 0}$ (24) & & & & \\
\hline Sex & & & 0.24 & $\mathbf{0 . 6 2}$ \\
Male (25) & 1 & 24 & & \\
Female (19) & 5 & 14 & & \\
\hline Tumor site & & & 0.19 & $\mathbf{0 . 6 4}$ \\
Frontal (22) & 2 & 20 & & \\
Parietal (8) & 0 & 8 & & \\
Temporal (5) & 1 & 4 & & \\
Occipital (9) & 3 & 6 & & \\
\hline $\begin{array}{l}\text { Grade } \\
\text { Grade I (3) }\end{array}$ & 0 & 3 & 4.93 & $\mathbf{0 . 0 2 6 *}$ \\
Grade II (6) & 0 & 6 & & \\
Grade III (15) & 2 & 13 & & \\
Grade IV (20) & 4 & 16 & & \\
\hline
\end{tabular}

*Statistically significant $(P<0.05) . \times 2$ : Chi-square test.

Recently in 2019, Abdulghani et al. similarly discovered positive EGFR expression in $15.9 \%$ of grade IV astrocytoma whereas all cases of grade I, II, III were negative.

These divergent IHC results can be due to different applied antibodies in different studies, differences in tissue processing and interobserver discrepancies in the subjective assessment of results (Marquez et al., 2004).

On the other hand, one of the well-known immunohistochemical methods for assessing the proliferation rate is $\mathrm{Ki} 67 \mathrm{LI}$, though previous studies that used it in grading gliomas and astrocytomas have shown conflicting results. The heterogeneity in Ki-67 LI between different specimens and different fields of the same specimen, made the average values of Ki67 $\mathrm{LI}$ more representative of the proliferative potential of the tumor more than the maximal Ki67 value (Chaloob et al., 2012).

The present study showed that all different grades of astrocytomas showed ki67 positivity with $\mathrm{Ki} 67 \mathrm{LI} 17.76 \% \pm 2.46$ with a range of $0 \%$ to $70 \%$. In the main time, there was a statistically significant relation between $\mathrm{Ki} 67 \mathrm{LI}$ and tumor grade where $\mathrm{Ki67} \mathrm{LI}$, and in turn tumor proliferation, increased with higher grades $(p>$ 0.001 ). There was no significant statistical relation between Ki67 LI and age, sex or site of astrocytoma.

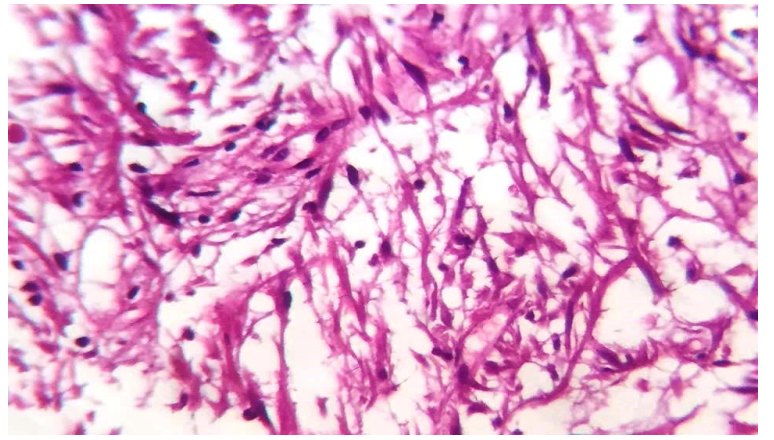

Figure 1. Pilocytic astrocytoma (Grade I) showing biphasic pattern of piloid areas showing neoplastic cells with long bipolar processes and spongy loosely textured areas (H\&E $x$ 100).

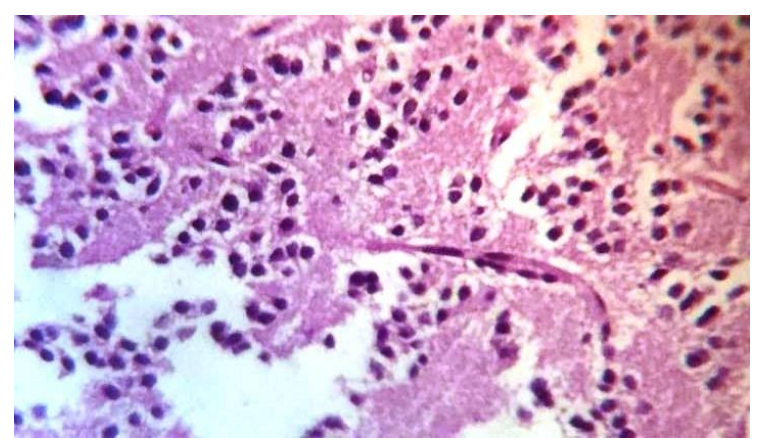

Figure 2. Low grade diffuse astrocytoma (Grade II) with diffuse growth pattern, moderate cellularity, irregular distribution and low grade nuclear atypia (H\&E x 200).

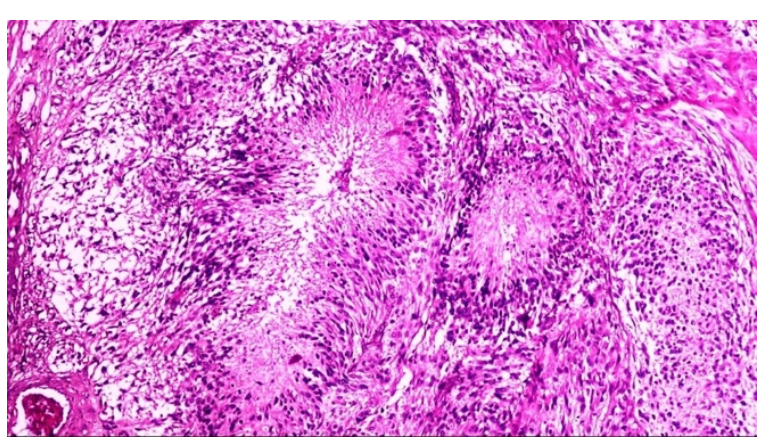

Figure 3. Glioblastoma multiforme (Grade IV) showing high grade anaplasia, mitotic activity with psedopalisading necrosis (H\&E x 100).

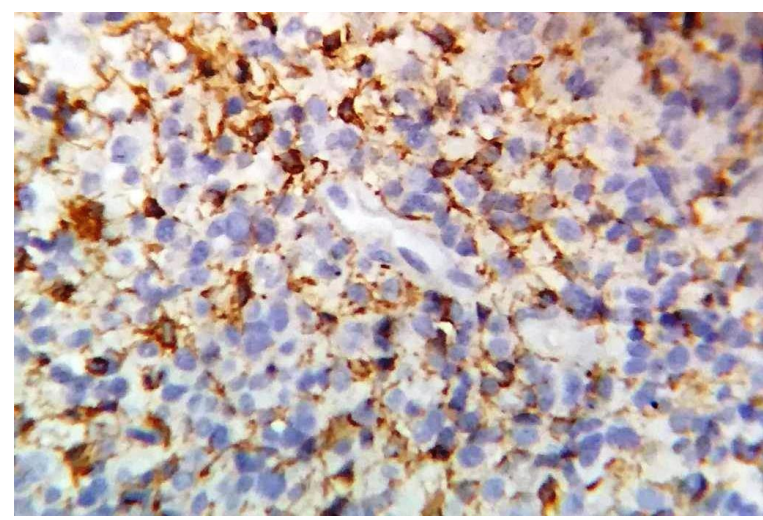

Figure 4. Weak EGFR membranous and cytoplasmic expression in low grade astrocytoma (x400). 


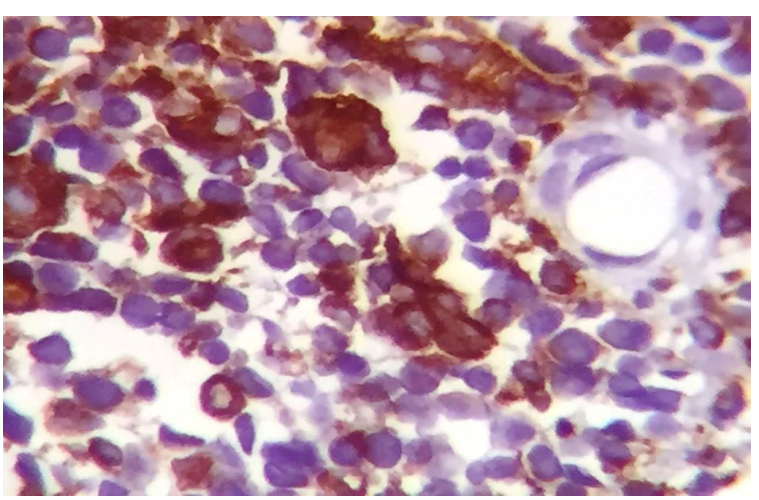

Figure 5. Strong EGFR expression in high grade astrocytoma (x400).

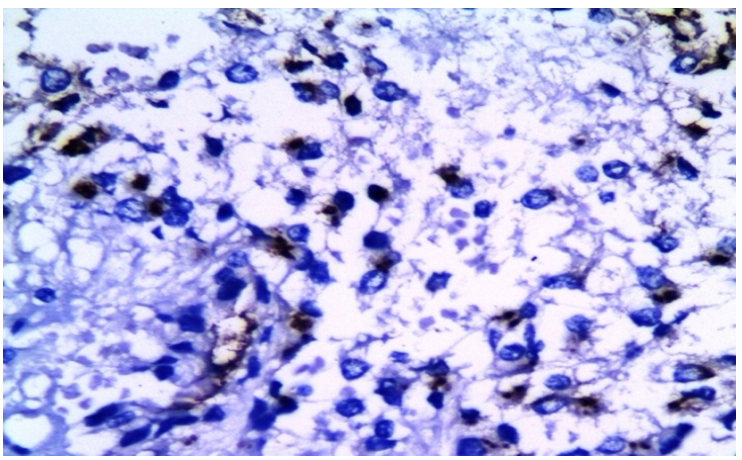

Figure 6. Low nuclear Ki67 $\mathrm{LI}$ in the nuclei of low grade astrocytoma (x200).

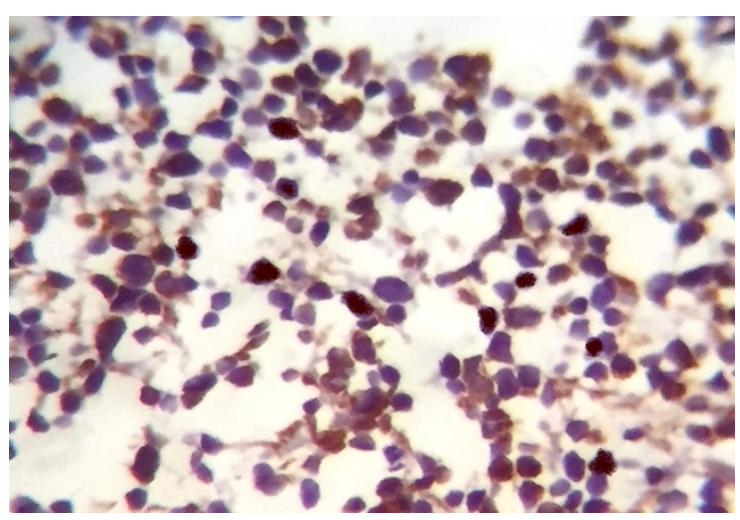

Figure 7. High Ki67 LI in high grade anaplastic astrocytoma (x200).

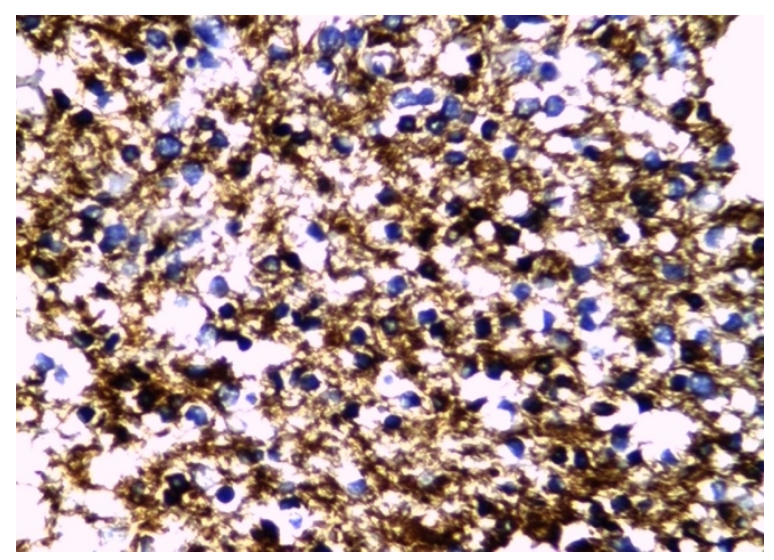

Figure 8. GFAP strong cytoplasmic expression in low grade astrocytoma (x200).

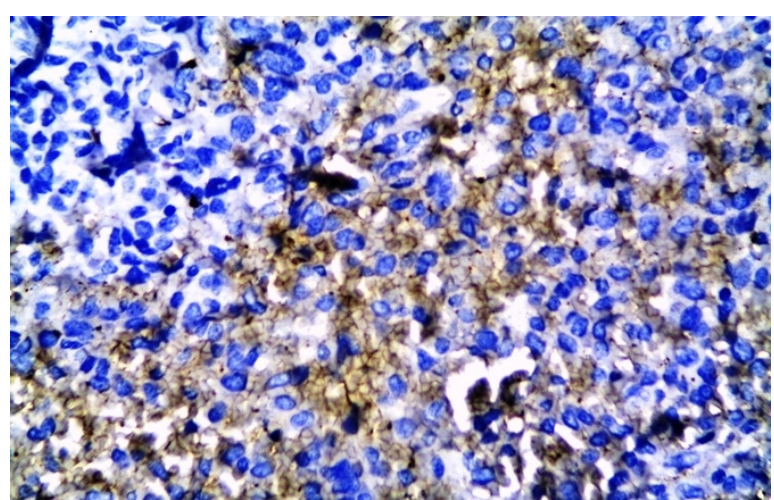

Figure 9. GFAP weak cytoplasmic expression in anaplastic astrocytoma (x200).

In approval with our results, Das et al. (2018) found the mean Ki67 LI increasing with increased tumor grade, in Grade I astrocytomas was 4.66, in Grade II astrocytomas was 8.07, in Grade III astrocytomas was 13.5, in Grade IV astrocytomas was 22.93. Also, there was a highly significant relation between the histopathological grade of astrocytomas and Ki67 LI $(p<0.05)$. This was close to the results found earlier in 2006, by Johnnessen et al. They reviewed the results of previous 16 studies. These studies showed an increase in Ki67 LI with the increasing tumor grade with a statistically significant difference between the indices of low grade II and high-grade tumors (grade III and IV) $(P<0.05)$, but not between grade III and grade IV tumors ( $P>0.05)$.

In 2014, Thotakura et al. as well, stated that Ki67 LI increased with the tumor grade with significant difference between all grades of astrocytoma except between Grade I and Grade II tumors. On studying Ki67 expression in gliomas, both Hu et al. (2013) and Belghali et al. (2017) noted that Ki-67 is more expressed in the high grade gliomas with a very significant difference between the various glioma grades.

Interestingly, Shivaprasad et al. (2017) noticed that the mean Ki67 LI in Grades I, II, III, and IV was $0.02,0.81,9.14$, and 17.81 , respectively with a statistically significant difference between Ki67 LI of LG (Grade II) and HG astrocytomas (Grades III and IV). They also observed significant increase in Ki67 LI in 90\% of high grade astrocytomas and non-significant increase in the remaining $10 \%$ of cases. Worth mentioning that there was an overlap of Ki67 LI between the different grades as the values of the glioblastomas could be as low as Grade II 
tumors, indicating that $\mathrm{Ki}-67 \mathrm{LI}$ cannot be used alone as a diagnostic measure.

These conflicted results can be attributed to the different fixatives used, immunohistochemical procedures, especially antigen retrieval, and variable interpretation of the immunostaining results. The low Ki67 $\mathrm{LI}$ value in high-grade astrocytoma could be the result of inadequate tissue sampling or using computer-assisted methods for assessment of Ki67 $\mathrm{LI}$ that may underestimate $\mathrm{LI}$ compared to manual methods (Das et al., 2018).

An accurate diagnosis of a neoplasm is a crucial factor in prognosis as well as in predicting response to therapy. Hundreds of antibodies have been suggested as potential diagnostic markers for gliomas including astrocytomas, but only a handful have turned out to be reliable. The most effective was GFAP for glial differentiation and demonstrating tumor astrocytic lineage (Paulus, 2009).

In this study, GFAP showed cytoplasmic expression $86.4 \%$ of studied cases with areas of necrosis in glioblastomas showing no immunostaining and the palisading cells showing positive staining. GFAP expression was higher in LG astrocytomas than in HG astroctyomas. The intensity of GFAP expression was inversely related to tumor grade with decreased intensity in higher grades $(p=0.015)$. A statistically significant inverse relation between GFAP expression and tumor grade where GFAP expression decreased with higher grades $(p=0.026)$.

Goyal et al. (2015) approved with our results by demonstrating that $81 \%$ of their studied glial tumors were widely reactive for GFAP. The staining pattern of GFAP in high grade astrocytomas was more variable. More anaplastic areas of the tumors showed less positivity. They suggested that GFAP immunostain helped in the objective assessment of the degree of differentiation in astrocytomas as astrocytic nature of the tumor was confirmed by demonstration of GFAP in less anaplastic foci. They added that positive GFAP staining helped overcoming histopathological diagnostic dilemmas in some undifferentiated tumors and to categorizing these tumors as glioblastomas.
Similarly, Belghali et al. (2017) showed that GFAP staining was variable according to the type and the grade of the tumor. They also noticed a lack of expression in almost half of the cases and that GFAP expression was relatively strong in the low grade compared with the high grade (31\% and $6 \%$, respectively) though, the difference was not statistically significant $(P=$ 0.149).

A wider scale of positivity was observed earlier by Haah et al. in 1991. They noticed positive GFAP staining in all astrocytic tumor cases. Furthermore, they suggested that immunostaining patterns of glioblastomas is different from that of astrocytoma grade II and III. Compared to the more differentiated astrocytomas, grade II, grade III, grade IV showed focally unstained foci implying the decrease of staining with the decrease of degree of differentiation.

Many other studies as well noted GFAP positivity in all studied astrocytic tumors (Cosgrove et al., 1993, Oh et al., 1999 and Goswami et al., 2007). Recently in 2019, van Bodegraven et al. found that GFAP positive cells were present in all grades of malignancy with decreased GFAP levels with increasing astrocytoma grade. Interestingly, in their study, a significant correlation was not consistently found which may be attributed to intra- and inter-tumor heterogeneity of GFAP positive cell localization, morphology, and GFAP variants.

The variability of results between our study and some of the previously mentioned ones can be explained by the heterogeneity of GFAP expression within the same tumor and the application of different staining protocols (Jaiswal, 2016).

Because of these discrepancies and the small sample size in this study, we recommend further studies with larger number of studied cases to emphasize on the role of these markers in the grading and prognosis of astrocytic tumors. Also, the relation between the expression of these markers and disease recurrence and disease free survival are needed to be investigated for their great effect on the prognosis. 


\section{CONCLUSION}

Assessment of the expression of EGFR, Ki67 and GFAP is sufficient for diagnosis and grading of astrocytomas, and can be recommended for application in clinical practice. Due to a greater spread of values of Ki67 between the various grades of astrocytoma and the heterogenicity of EGFR and GFAP expression within tumor tissue, these markers should be used in combination as a panel side by side with established criteria of histological malignancy and WHO grading system for accurate diagnosis and grading with subsequent close association to prediction of astrocytic tumors prognosis. Further studies should be carried out on larger scales for more confirmation of our results and approving the validity of this panel.

\section{CONFLICTS OF INTEREST}

All authors declared no conflicts of interest.

\section{FUNDING}

No fund was received for this work.

\section{REFERENCES}

Abdulghani MM, Abbas MN, Mohammed WR. (2019). Immunohistochemical Expression of Epidermal Growth Factor Receptor in Astrocytic Tumors in Iraqi Patients. Macedonian J Med Sci. 7: 3514.

Agosti RM, Leuthold M, Gullick WJ, Yasargil MG, Wiestler OD. (1992). Expression of the epidermal growth factor receptor in astrocytic tumours is specifically associated with glioblastoma multiforme. Virchows Archiv A. 420: 321-325.

Belghali MY, Rais H, Ba-M'hamed S, Hazmiri FZ, EI Khoudri N, Fakhri A, Belbachir A, Elkhiraoui H, Hakmaoui A. (2017). Glial fibrillary acidic protein, CD34, Ki-67, and p53 immunohistochemistry expression study to estimate the concordance between the morphology and the awarded grades of the brain gliomas. Clinical Cancer Investigation Journal. 6: 44.

Burel-Vandenbos $F$, Benchetrit $M$, Miquel $C$, Fontaine D, Auvergne R, Lebrun-Frenay C, Cardot-Leccia N, Michiels JF, Paquis-Flucklinger V, Virolle T. (2011). EGFR immunolabeling pattern may discriminate low-grade gliomas from gliosis. Journal of Neuro-Oncology. 102: 171-178.

Carvalho PO, Uno M, Oba-Shinjo SM, Rosemberg S, Wakamatsu A, da Silva CC, Teixeira MJ, Marie
SK. (2014). Activation of EGFR signaling from pilocytic astrocytomas to glioblastomas. The International journal of biological markers. 29: 120-128.

Chaloob MK, Ali HH, Qasim BJ, Mohammed AS. (2012). Immunohistochemical expression of Ki67, PCNA and CD34 in astrocytomas: a clinicopathological study. Oman medical journal. 27: 368.

Cosgrove MM, Rich KA, Kunin SA, Sherrod AE, Martin SE. (1993). Keratin intermediate filament expression in astrocytic neoplasms: Analysis by immunocytochemistry, western blot, and northern hybridization. Mod Pathol. 6: 342347.

Das B, Raj KV, Atla B. (2018). Clinicohistopathological study of astrocytomas along with Ki-67 proliferative index. Int J Res Med Sci. 6: 665670.

Goswami C, Chatterjee U, Sen S, Chatterjee S, Sarkar S. (2007). Expression of cytokeratins in gliomas. Indian J Pathol Microbiol. 50: 478-481.

Goyal R, Mathur SK, Gupta S, Goyal R, Kumar S, Batra A, Hasija S, SenR. (2015). Immunohistochemical expression of glial fibrillary acidic protein and CAM5. 2 in glial tumors and their role in differentiating glial tumors from metastatic tumors of central nervous system. Journal of neurosciences in rural practice. 6: 499.

Guillaudeau A, Durand K, Pommepuy I, Robert S, Chaunavel A, Lacorre $S$, DeArmas $R$, Bourtoumieux S, El Demery M, Moreau JJ, Labrousse F. (2009). Determination of EGFR status in gliomas: usefulness of immunohistochemistry and fluorescent in situ hybridization. Applied Immunohistochemistry \& Molecular Morphology. 17: 220-226.

Haah LE, Chong YG, Chu JW, Lee KC, Chae YS. (1991). Immunohistochemical Study of Gliomas using Glial Fibrillary Acidic Protein (GFAP), S-100 Protein, and Neurofilament. Journal of Korean Neurosurgical Society. 20: 389-398.

Hu X, Miao W, Zou Y, Zhang W, Zhang Y, Liu H. (2013). Expression of p53, epidermal growth factor receptor, Ki-67 and 06-methylguanine-DNA methyltransferase in human gliomas. Oncology letters. 6: 130-134.

Jaiswal S. (2016). Role of immunohistochemistry in the diagnosis of central nervous system tumors. Neurol India.64: 502-512.

Johannessen AL, Torp SH. (2006). The clinical value of Ki-67/MIB-1 labeling index in human astrocytomas. Pathology \& Oncology Research. 12: 143.

Louis DN, Perry A, Reifenberger G, Von Deimling A, Figarella-Branger $D$, Cavenee WK, Ohgaki $H$, Wiestler OD, Kleihues P, Ellison DW. (2016). The 
2016 World Health Organization classification of tumors of the central nervous system: a summary. Acta neuropathologica. 131: 803820.

Maiti AK, Ghosh K, Chatterjee U, Chakrobarti S, Chatterjee S, Basu S. (2008). Epidermal growth factor receptor and proliferating cell nuclear antigen in astrocytomas. Neurology India. 56: 456.

Marquez A, Wu R, Zhao J, Tao J, Shi Z. (2004). Evaluation of Epidermal Growth Factor Receptor (EGFR) by Chromogenic In Situ: Hybridization $\left(\mathrm{CISH}^{\mathrm{TM}}\right)$ and Immunohistochemistry (IHC) in Archival Gliomas Using Bright-Field Microscopy. Diagnostic Molecular Pathology. 13: 1-8.

Oh D, Prayson RA. (1999). Evaluation of epithelial and keratin markers in glioblastoma multiforme: An immunohistochemical study. Arch Pathol Lab Med. 123: 917-920
Paulus W. (2009). GFAP, Ki67 and IDH1: perhaps the golden triad of glioma immunohistochemistry. Acta neuropathologica. 118: 603.

Popova SN, Bergqvist M, Dimberg A, Edqvist PH, Ekman S, Hesselager G, Ponten F, Smits A, Sooman L, Alafuzoff I. (2014). Subtyping of gliomas of various WHO grades by the application of immunohistochemistry. Histopathology. 64 :365-379.

Thotakura M, Tirumalasetti N, Krishna R. (2014). Role of Ki-67 labeling index as an adjunct to the histopathological diagnosis and grading of astrocytomas. Journal of cancer research and therapeutics. 10: 641 .

van Bodegraven EJ, van Asperen JV, Robe PAJ, Hol EM. (2019). Importance of GFAP isoformspecific analyses in astrocytoma. Glia. 67: 1417-1433. 


\section{Egyptian Association for Cancer Research (EACR)}

http://eacr.tanta.edu.eg/

EACR is an NGO society that was declared by the Ministry of Social Solidarity (Egypt) No. 1938 in 19/11/2014 based on the initiative of Prof. Mohamed Labib Salem, the current Chairman of EACR. EACR aims primarily to assist researchers, in particular young researchers in the field of cancer research through workshops, seminars and conferences. Its first international annual conference entitled "Anti-Cancer Drug Discovery" was successfully organized in April 2019 (http://acdd.tanta.edu.eg). Additionally, EACR aims to raise the awareness of the society about the importance of scientific research in the field of cancer research in prediction, early diagnosis and treatment of cancer. EACR is also keen to outreach the scientific community with periodicals and news on cancer research including peer-reviewed scientific journals for the publication of cutting-edge research. The official scientific journal of EACR is "International Journal of Cancer and biomedical Research (IJCBR: https://jcbr.journals.ekb.eg) was successfully issued in 2017 and has been sponsored by the Egyptian Knowledge Bank (EKB: www.ekb.eg).

\section{EACR Chairman,}

Prof. Mohamed Labib Salem, PhD

Professor of Immunology

Faculty of Science, Tanta Universiy, Egypt 


\section{GUIDE FOR AUTHORS}

Publisher :The International Journal of Cancer and Biomedical Research (IJCBR) is an International and interdisciplinary journal of preclinical and clinical studies in the area of cancer and biomedical research. It is a peer-reviewed journal in English, published quarterly (in March, June, September, and December) by the Egyptian Association for Cancer Research (EACR) in both print and online formats (4 issues making a volume). Special issues or supplements may also be produced from time to time upon agreement with the Editorial Board.

Scope :The main aim of IJCBR is to attract the best research in animal and human biology in health and diseases from across the spectrum of the biomedical sciences at the molecular, cellular, organ, and whole animal levels especially those that are related to cancer research, including causes, prediction, diagnosis, prognosis, and therapy.

Publication Fees :The journal does charge for submission, processing, or publication of manuscripts (2000 LE for Egyptians or $250 \$$ for non-Egyptians; EACR members receive 15\% discount on publication). Of them Peer-review fees (300 LE) should be paid on submission (non-refundable). For the fast-track production of the accepted manuscript, another 500 LE is paid.

General specifications for different types of article

- Submitted manuscripts should not have been published previously, except in a limited form (e.g. short communication to a symposium or as part of MSc or PhD theses) and should not be under consideration for publication by other journals.

- All co-authors should agree with the content of the manuscript. Authors must have obtained permission to use any copyrighted material in the manuscript before submission.

IJCBR publishes different types of articles

- Original Article (6000 words with $\mathbf{4}$ tables and $\mathbf{4}$ figures, maximum $\mathbf{8}$ display items): Articles with novel findings are the target of IJCBR. Articles presenting a detailed description of a new technique, comparison of existing methods, meta-analyses with comprehensive and in-depth discussion are considered. Papers in a numbered series are not accepted unless all are submitted at the same time.

- Short communications or case study (3000 words with $\mathbf{4}$ display items): Short communications present exceptionally exciting, novel or timely contents are considered. They will be peer-reviewed in the same way as research papers. The references are restricted to 15 .

- Reviews or systematic review (9000 words with $\mathbf{1 0}$ display items): They are invited by the Editorial Board or unsolicited. Review articles have to be contemporary and comprehensive and add information to the knowledge. Sharp critical analyses of novel data or concepts are encouraged. When relevant, a statistical analysis of data and a meta-analysis approach are recommended.

- Opinion papers, letter to the editor or comment to the editor (1500 words with $\mathbf{2}$ display items): They are submitted by invitation of the Editorial Board. They are short papers, which aim to inform scientists, industry, and the public and policymakers about cutting-edge issues in research or the impact of research. They reflect the opinion of their authors who bear full responsibility of the published paper. The references are restricted to 10 .

- Conference/Symposium papers: The journal will consider for publication the results of original work and critical reviews that are presented at conferences/symposia. Symposium organizers who wish to publish bundles of papers from a symposium/conference in IJCBR should first contact the Editor-in-Chief of the IJCBR (EACR@unv.tanta.edu.eg) for agreement. Supplementary material can be proposed and will be made available online. The responsibility for the preparation of a paper in a form suitable for publication lies with the author.

- Thesis: IJCBR can publish the summary and abstract of Master and PhD theses in a special issue.

English: Good quality of written English is required. Spelling may be in British or American English but must be consistent throughout the paper. Care should be exercised in the use of biological terminology that is ill-defined or of local familiarity only. We recommend that authors have their manuscripts checked by an English language native speaker before submission.

Manuscript layout: Manuscripts should be prepared using a standard word processing program and presented in a clear readable format with easily identified sections and headings. The manuscript layout is based on the following directions.

- The main text contains Title, Abstract, Keywords, Introduction, Material and Methods, Results, Discussion, References, Tables, figures.

- The title needs to be concise and informative. Use bold, with an initial capital for the first word only and for words that ordinarily take capitals.

- Short (running) title (max 80 characters including spacing).

- The article text should be typed with double line spacing with wide margins $(2.5 \mathrm{~cm})$.

- The lines must be continuously numbered; the pages must also be numbered.

- Font Calibri 12 should be used for the text, and 12 for the tables, figure legends and references.

- The sections should typically be assembled in the following order:

- Title page contains title, authors' names, full affiliations, acknowledgements and the corresponding author's contacts and Short title.

Abstract (max 250 words, single paragraph): The abstract should be complete and understandable without citation, references, table, or figure. Use structured abstract: Background, Aim, Materials \& Methods, Results and Conclusion. The context and the rationale of the study are presented succinctly to support the objectives. The experimental methods and main results are summarized but should not be overburdened by numerical values or probability values. The abstract ends with a short and clear conclusion. 
Keywords: Up to five short and specific keywords should complement the title with respect to indicating the subject of the paper in alphabetic order.

Introduction: The introduction briefly outlines the context of the work, presents the current issues that the authors are addressing and the rationale to support the objectives, and clearly defines the objectives.

Material and methods: Material and methods should be described in sufficient details so that others can repeat the experiment. Reference to previously published work may be used to give methodological details, provided that said publications are readily accessible and in English. The code of ethics should be followed for all experiments use animals or human samples.

Statistical analysis of results: The statistical design and the models of statistical analysis must be described, as well as each of the statistical methods used. Sufficient statistical details must be given to allow replication of the statistical analysis. The experimental unit should be defined (e.g., individual or group of animals).

Results: Data are presented as tables and figures. Brief description of the results for each table and figure should be presented. Unpublished data can be mentioned when necessary.

Discussion: Should be separate from the Results section and should focus only on intra- and inter-data discussion (the data in the results section) as well as with the relative data in the literature. Don't repeat information already presented in the Introduction section. Start the first paragraph in the Discussion with a paragraph stating the rationale behind the study, the objectives, and the main findings. End Discussion with a short conclusion.

Acknowledgements: In this section, the authors may acknowledge (briefly) their support staff.

Conflict of interest: All papers with a potential conflict of interest must include a description/explanation in a separate heading.

Funding details: The authors should state the source of findings of the study (with research funder and/or grant number). If no fund, the authors should state that the study is self-funded.

\section{References}

Citation of references: In the text, references should be cited by the author(s) surname(s) and the year of publication (e.g. Salem, 2020). References with two authors should be cited with both surnames (e.g. Salem and Meshrif, 2021). References with three or more authors should be cited with the first author followed by et al. (in italics; e.g. Salem et al., 2021). Names of organizations used as authors (e.g. Food and Drug Administration) should be written out in full in the list of references and on the first mention in the text. Subsequent mentions may be abbreviated (e.g. FDA).

- List of references. Literature cited should be listed in alphabetical order by authors' names. It is the author's responsibility to ensure that all references are correct. All authors should be written and so the full journal name.

- $\quad$ References from journal articles are formatted in APA as this example: Al-Amoudi WM (2018). Toxic effects of Lambdacyhalothrin on the rat thyroid. Involvement of oxidative stress and ameliorative effect of ginger extract. Toxicology Reports, 5: 728-736.

- $\quad$ References from books or official reports are formatted as this example. Kebreab E, Dijkstra ANM, Bannink A, Gerrits WJJ, \& France J (2006). Nutrient digestion and utilization in farm animals. CABI Publishing. Wallingford, UK.

- References from chapters or parts of books are formatted as this example. Nozière $P, \&$ Hoch $T$ (2006). Modelling fluxes of volatile fatty acids from rumen to portal blood. In: Nutrient digestion and utilization in farm animals (Kebreab E, Dijkstra ANM, Bannink A, Gerrits WJJ \& France J, eds.), pp. 40-47. CABI Publishing. Wallingford, UK.

Tables: The data should be presented in tables or in graphs, not both.

- Each table should be placed on a separate page at the end of the main text.

- Tables are numbered consecutively using Arabic numbering. They are referred to as Table 1 , Table 2, etc., with capital ' $T$ ', no italics

- $\quad$ Each table has its explanatory caption. The caption is sufficient to permit the table to be understood without reference to the text.

- Abbreviations used in tables/figures have to be defined either as footnotes or in the caption.

\section{Figures}

- $\quad$ Package the figures in a single PowerPoint file. Each figure in a separate slide.

- Figure size should be readable in a width of approximately 8-175 $\mathrm{mm}$ (i.e. the maximum size of printing over two columns).

- Ensure that the font size is large enough to be readable at the final print size, use Calibri font to ensure that they are consistent throughout the figures.

- $\quad$ The figures should preferably be provided as TIFF or EPS files.

- The resolutions of figures must be at least $300 \mathrm{dpi}$.

- Preparation of images for a manuscript: For guidance, we refer to the Journal of Cell Biology's instructions to authors (http://jcb.rupress.org/site/misc/ifora.xhtml\#image_aquisition).

- If a cropped image is included in the main text of a paper (e.g. a few lanes of a gel), display the full original image, including the appropriate controls, the molecular size ladder and/or the scale as relevant, as a single figure in a Supplementary Material file to facilitate peer-review and for subsequent online publication.

- Supplementary material is submitted along with the main manuscript in a separate file and identified at uploading as "Supplementary File - for Online Publication Only" The title of the article is included at the top of the supplementary material.

Corresponding author's guidelines: Upon acceptance the corresponding author is required to send his/her recent formal photo to be attached to the front page of the article. 


\title{
International Journal of Cancer \& Biomedical Research
}

(IJCBR) Online ISSN 2682-2628

\author{
Editor-in-Chief \\ Mohamed Labib Salem, PhD \\ Tanta University, Egypt
}

\begin{tabular}{l} 
EACR Board \\
\hline Nehal Elmashad, MD \\
Tanta University, Egypt \\
Nabil Mohy Eldin, PhD \\
Kafrelsheikh University, Egypt \\
Doaa Al-Ghareeb, PhD \\
Alexandria University, Egypt \\
Abdel-Aziz Zidan, PhD \\
Damanhour University, Egypt
\end{tabular}

\begin{tabular}{l} 
Managing Editor \\
\hline Wesam Meshrif, PhD \\
Tanta University, Egypt \\
Sohaila Galal, PhD \\
Tanta University, Egypt \\
Production and Contact \\
\hline Hamdi Kandil \\
Tanta University, Egypt \\
Email: ljcbr100@gmail.com
\end{tabular}

\section{Advisory Board}

Alberto Montero, MD

Taussig Cancer Center, Cleveland,

USA

Yi Zhang, MD

Zhengzhou University, China

Mark Robunstein, Ph D

Medical University of South

Carolina, USA

Mohsen Farid, Ph D

Derby University, USA

Natarajan Muthusamy, Ph D

Ohio State University, USA

Hideki Kasuya, MD

Nagoya University, Japan

Sherif El-Khamisy, Ph D

Sheffield University, UK

Mohamed Ghanem, Ph D

Kafr Elshikh University, Egypt

Sayed Bakry, Ph D

Alazhar University, Egypt

Sameh Ali, Ph D

Nationa Liver Institute, Egypt

Gamal Badr, Ph D

Assuit University, Egypt

Nadia Hamdy, Pharm D

Ain Shams University, Egypt

\section{Editorial Board}

\section{Clinical studies}

Hesham Tawfik, MD

Tanta University, Egypt

Mohamed Attia, MD

Tanta University, Egypt

Mohamed Elshanshory, MD

Tanta University, Egypt

Essam Elshiekh, MD

Tanta Cancer Center, Egypt

Rasha Eraky, MD

Tanta University, Egypt

Shaima Abou-Kjatwa, MD

Tanta University, Egypt

Marcela Diaz, MD

Cleveland Clinic Foundation, USA

Mohamed Abou-El-Enein, MD

Charité Universitätsmedizin Berlin,

Germany
Alaa Eldin Almostafa, MD

McGill University, Canada

Olfat Gadallah, MD

Tanta University, Egypt

Nagla Sarhan, MD

Tanta University, Egypt

Naglaa Fathy, Pharm D

Zagazik University, Egypt

Mohamed Salama, MD

Mansoura University, Egypt

Mona Marie, MD

Alexandria University, Egypt

Preclinical studies

Mostafa El-Sheekh

Tanta University, Egypt

El-Refai Kenawy, Ph D

Tanta University, Egypt

Mohamed Noureldin, Ph D

Banaha University, Egypt

Yousry Albolkiny, Ph D

Tanta University, Egypt

Elsayed Salim, Ph D

Tanta University, Egypt

Shengdian Wang, Ph D

Chinese Academy of Sciences,

China

Sabry El Naggar, Ph D

Tnata Univesity, Egypr

Faris Alenzi, Ph D

Prince Sattam bin Abdulaziz

University, KSA

Ibrahim El-Sayed, Ph D

Menoufia University, Egypt

Tarek Aboul-Fadl, Ph D

Assiut University, Egypt

Rabab Khairat, Ph D

National Research Center,

Giza, Egypt

Wael Lotfy, Ph D

Alexandria University, Egypt

Ashraf Tabll, Ph D

National Research Center, Egypt

Nahla Shoukry, Ph D

Suez University, Egypt
Medhat Eldenary, Ph D

Tanta University, Egypt

Azza Hasan, Ph D

Menufia University, Egypt

Nanees Gamal Eldin, Ph D

Tanta University, Egypt

Mohamed Mansour, UK

Sabbah Hammoury, Ph D

Alexandria Ayadi Almostaqba

Oncology Hospital, Egypt

Nehal Aboulfotoh, Ph D

Zewail City for Science and

Technology, Cairo, Egypt

Amir Elkhami, Ph D

Galaxo, San Francisco, USA

Ahmed Alzohairy, Ph D

Zagazi University, Egypt

Wgady Khalil, Ph D

National Research Center, Egypt

Amr Amin, Ph D

United Arab Emirates

University, UAE

AbdelRahman Zekri, Ph D

National Cancer Institute, Egypt

Hussein Khamis, Ph D

Alexandria University, Egypt

Magdy Mahfouz, Ph D

Kafr Elsheikh University, Egypt

Ehab Elbedewey, Ph D

Tanta University, Egypt

Abeer Badr, Ph D

Cairo University, Egypt

Mamdooh Ghoneum, Ph D

Charles Drew University of

Medicine \& Science, USA

Haiam Abou Elela, Ph D

National Institute of Oceanography and Fisherie, Egypt

Maha EL-Demellawi, Ph D City for Scientific Research \&

Technology Applications, Egypt

Desouky Abd-El-Haleem, Ph D

City for Scientific Research \&

Technology Applications, Egypt 